\title{
Study of the effect of developmental care on very low birth weight newborns: Experience of neonatology center -Rabat
}

\author{
G Bouazza $^{1}$, L Drame ${ }^{1}$, FZ Lamirii ${ }^{1}$, N Chahid ${ }^{1}$, A Ansari Chenguiti ${ }^{2}$ and A Barkat ${ }^{1 *}$ \\ ${ }^{1}$ National Reference Center in Neonatology-RABAT-Chis Ibn Sina, Maternal-child Couple Health and Nutrition Research Team, Faculty of Medicine and \\ Pharmacy of Rabat, Mohammed V university , Rabat, Morocco \\ ${ }^{2}$ Hospital CheikhZaid / University Abulcassis, Morocco
}

\begin{abstract}
Background: Developmental care for premature infants can be defined as all techniques that are not pharmacological, behavioral and environmental, to support its development in its neurological, behavioral, relational and cognitive components. The purpose of our study was to assess the impact of its developmental care in our service.

Materials and patients: This is a prospective comparative analytical study that took place between October 2016 to September 2017 . Children born before 37 weeks of Amenorrhea (GA) were included with a birth weight less than or equal to $1500 \mathrm{~g}$.

Results: Our study recorded 180 mother children including 100 with permanent accompaniment and 80 without permanent accompaniment. The average gestational age was $32.68 \pm 2.6$, the pregnancy was followed in $15.9 \%$, the average birth weight was $1450 \pm 40$. Skin to skin was practiced in $55 \%$ of cases. The mean discharge weight was $1692,70 \pm 533$ for those with permanent parental guidance, and $1515 \pm 25$ for those without. Median duration of hospitalization was more important in those who did not receive permanent support $\mathrm{p}(0.03)$. A statistically significant positive correlation was observed between the rate on apnea and skin to skin practice, it was the same for the rate of hypothermia.

Conclusion: Developmental care represents a new standard of care in neonatology of scientifically proven efficacy. Several elements supporting the importance of developmental care practices provided to the premature child have been clearly identified. They are essentially based on information and education of parents, training and support of health care team; if this practice has shown its effectiveness in developed countries, it is crucial to integrate it into neonatal care in our country. It will help to alleviate the lack of beds of neonatology for low birth weight.
\end{abstract}

\section{Introduction}

Developmental care for premature infants can be defined as all techniques that are not pharmacological, behavioral and environmental, to support its development in its neurological, behavioral, relational and cognitive components [1]. These techniques can be used in an isolated or associated way in integrated programs such as the NIDCAP [2].

They are a combination of interventions aimed at adapting the neonatal environment to the development of the preterm newborn.

The use of developmental care is theoretically justified by the existence of different physiological processes occurring during the perinatal period. The progress made in the medical care of premature children has reduced the mortality rate in the Neonatal period, without increasing the frequency of neurosensory sequelae, attributed to the quality of care provided to the Cerebral protection during their stay in resuscitation and neonatal medicine [3].

Kangaroo Care (SK) is an effective method of supporting low birth weights and is a good alternative, in developing countries such as Morocco, to alleviate the lack of conventional care [4]. The practice of skin-to-skin is recommended by many learned societies, WHO recommends it in the guidelines for the management of newborns as a means against hypothermia, promoting breastfeeding and promoting early interactions between the mother and the child [5].

The purpose of our study was to assess the impact of its developmental care in our service.

\section{Materials and methods}

\section{Type and period of study}

This is a prospective comparative analytical study that took place between October 2016 to September 2017.

\section{Place of study}

The study took place at the National Reference Centre for neonatology and Nutrition, which is a center located on the ground floor of the Rabat Child Hospital. Our Centre's current hospital capacity is estimated at 55 beds divided into three units:

- A 12-bed medico-surgical Neonatal resuscitation unit, providing assisted ventilation and the various acts of resuscitation essential for life-saving.

- An intensive care and post-resuscitation unit with 11 beds providing the various urgent care and monitoring outside the mechanical ventilation.

${ }^{\star}$ Correspondence to: Amina Barkat, Neonatology and Neonatal resuscitation reference Center -Rabat children hospital, Morocco, E-mail: barakatamina@ hotmail.fr

Key words: care, development, prematurity, neonatal medical and resuscitation service

Received: August 07, 2018; Accepted: August 31, 2018; Published: September 06, 2018 
- A standard care and rearing unit of 32 beds equipped with a room to receive the mothers who are breastfeeding their baby, recently arranged.

There are two units in the delivery room of Souissi maternity. In addition to its units, the center provides a day-hospital activity and has an emergency, functional area $7 \mathrm{~d} / 7$ and $24 \mathrm{~h} / 24$.

\section{Study population}

\section{Inclusion criteria}

Included in the study were all newborns weighing less than $1500 \mathrm{~g}$.

\section{Exclusion criteria}

We excluded the parents who refused to participate in the study, all newborns whose birth weight was greater than or equal to $1500 \mathrm{~g}$ and all post term.

Methods and instruments and data collection in order to identify all aspects related to our research theme, our study consisted, initially, of the recruitment of newborns to their admission, and in a second phase the development of an operating record that collected information on moms and newborns.

\section{The data listed concerned:}

- Demographic and socio-economic characteristics (Age, social situation, level of education, provenance, marital status). The woman was considered non-illiterate when she did not know how to write or read French.

- Health and obstetric characteristics (attendance, parity, medical and surgical history, pregnancy monitoring, delivery pathway). A pregnancy was followed when the woman had observed at least 3 prenatal visits.

- Neonatal and clinical characteristics at admission (age, sex, reason for hospitalization). The evolutionary parameters.

- parents were educated about skin-to-skin practice.

\section{Statistical analysis}

Statistical analysis was performed using SPSS software version 13.0; Quantitative variables were expressed in median with quartiles or on average \pm standard deviation, and qualitative variables in strength and percentage.

The Student T-Test and Chi 2 or Fisher's exact test were used respectively for the univariate comparison of quantitative variables and qualitative variables with a threshold of significance $<0.05$.

\section{Ethical considerations}

The Protocol of the study was submitted to the Ethics Committee of the Faculty of Medicine and Pharmacy of Rabat for approval.

\section{Results}

During the study period, 180 mother children including 100 with permanent accompaniment and 80 without permanent accompaniment.

\section{Maternal characteristics (Table 1)}

The average gestational age was $36.68 \pm 2.6$. Newborns were born of a pregnancy followed in $46.67 \%$ with an urban origin in $48.89 \% .60 \%$ newborns were born by cesarean section.
Table 1. Maternal characteristics

\begin{tabular}{|c|c|}
\hline Variable & $\begin{array}{l}\text { Mother population } \\
\mathrm{N}=\mathbf{1 8 0}\end{array}$ \\
\hline Gestational age $\pi$ & $32.68 \pm 2.6$ \\
\hline Maternal age & $28.2 \pm 5.17$ \\
\hline \multicolumn{2}{|l|}{ Martial status $^{z}$} \\
\hline Married & $178(99)$ \\
\hline no & $2(1)$ \\
\hline \multicolumn{2}{|l|}{ Pregnancy follow $u^{b \neq}$} \\
\hline No & $96(53.33)$ \\
\hline Yes & $84(46.67)$ \\
\hline \multicolumn{2}{|l|}{ Mode of Delivery $^{*}$} \\
\hline Césarien & $72(40)$ \\
\hline Normal delivery & $108(60)$ \\
\hline \multicolumn{2}{|l|}{ Living Environment ${ }^{*}$} \\
\hline Urban & $88(48.89)$ \\
\hline Rural & $92(51.11)$ \\
\hline \multicolumn{2}{|l|}{ Social coverage $e^{z}$} \\
\hline No & $68(37.77)$ \\
\hline Ramed & $84(46.66)$ \\
\hline Mutual & $28(15.56)$ \\
\hline \multicolumn{2}{|l|}{ Educational level $^{¥}$} \\
\hline Non-Literate & $99(55)$ \\
\hline Primary & $41(22.78)$ \\
\hline Secondary & $32(17.78)$ \\
\hline Higher & $8(4.44)$ \\
\hline Skin to skin practices & $100(55.56)$ \\
\hline
\end{tabular}

The values are expressed on average \pm standard deviation (ף) or efective and percentage (¥); Ramed: Minestry of health coverage

The absence of any level of education (illiteracy) among parents was noted in 55\% (Table 2).

The median age in admission was 0 day [0-1]. Female sex was represented in $51.11 \%$ of cases.

The main diagnoses were dominated by respiratory distress associated with prematurity (30.55\%) and neonatal jaundice $6.11 \%$ (Table 2).

From the analysis in table 3 , the accompanying newborns were less likely to stay in comparison with the unaccompanied $(\mathbf{P}=\mathbf{0 . 0 3})$, the same for the weight at the discharge $(\mathbf{p}=\mathbf{0 . 0 4 8})$ with an Average daily intake of $28 \pm 4 \mathrm{~g}$.

The analysis of Table 4 revealed a statistically significant positive correlation $(\mathrm{P}=0.042)$ between weight gain and skin to skin practices (or $=0.09$ [0.2-0.7], The same for respiratory distress (or=0.25 [0.5$0.96]$ ), and hypothermia (or $=1.8[2.1-4.3]$ ).

\section{Discussion}

In our study the mean maternal age of $28.2 \pm 5,17$, corresponds to what was observed in many series or the average age of mothers varied around 27 years $[6,7]$.

Families were socially characterized by poverty and a low level of mother education. A low socio-economic level associated with prematurity and low birth weight had been observed in other countries [8].

In our study skin-to-skin was practiced by 100 mothers, many studies on "kangaroo mother care" or "skin-to-skin care" have also shown that the care environment is ideally provided by the maternal body.

The premature who benefited from this practice stayed less in hospital with regular weight gain, our results are similar to those of P.M. Faye et al in Senegal [9]. 
Table 2. Distribution of study population by clinical and neonatal characteristics $(\mathrm{N}=421)$

\begin{tabular}{|l|l|}
\hline Variables & Newborns \\
\hline Neonatal characteristics & N=180 \\
\hline Admission Newborn Age (Day) & \\
\hline Sex & \\
\hline Male & $0[0-1]$ \\
\hline Female & \\
\hline Weight at admission $(\mathrm{g})^{\mathrm{a}}$ & $88(48.89)$ \\
\hline Weight at discharge $(\mathrm{g})^{\mathrm{a}}$ & $92(51.11)$ \\
\hline Size at admission $(\mathrm{cm})^{\mathrm{a}}$ & $1450 \pm 40$ \\
\hline Size at the exit $(\mathrm{cm})^{\mathrm{a}}$ & $1580 \pm 30$ \\
\hline Cranial perimeter at admission $(\mathrm{cm})^{\mathrm{a}}$ & $40 \pm 5$ \\
\hline Cranial perimeter at the exit $(\mathrm{cm})^{\mathrm{a}}$ & $45.1 \pm 8$ \\
\hline Clinical characteristics & \\
\hline Respiratory distress & $31.9 \pm 2$ \\
\hline Jaundice & $34 \pm 2$ \\
\hline Perinatal Asphyxia & \\
\hline Infection & $55(30.56)$ \\
\hline Intrauterin Growth delay & $11(6.11)$ \\
\hline
\end{tabular}

${ }^{\mathrm{a}}$ mean \pm sd; ${ }^{*}$ effective (\%); ${ }^{\mathrm{E}}$ median [quartiles]

Table 3. Comparative analysis between the 2 newborn groups (accompanied and unaccompanied)

\begin{tabular}{|c|c|c|c|}
\hline Variables & $\begin{array}{l}\text { Newborns } \\
\text { accompanied }\end{array}$ & $\begin{array}{l}\text { Unaccompanied } \\
\text { newborns }\end{array}$ & $p$ \\
\hline Weight at the exit (g) ${ }^{a}$ & $1692,70 \pm 533$ & $1515 \pm 25$ & 0.048 \\
\hline Size at the exit $(\mathrm{cm})^{\mathrm{a}}$ & $47,1 \pm 8$ & $43,8 \pm 4$ & 0.56 \\
\hline $\begin{array}{l}\text { Cranial Perimeter } \\
\text { at the exil }(\mathrm{cm})^{\mathrm{a}}\end{array}$ & $36 \pm 6$ & $33,9 \pm 8$ & 0.049 \\
\hline Length of stay (day) & $17[7-28]$ & $23[12-58]$ & 0.03 \\
\hline $\begin{array}{l}\text { Breastfeeding at } \\
4 \text { months }^{*}\end{array}$ & & & 0.002 \\
\hline Yes & $98(98)$ & $52(52)$ & \\
\hline No & $2(2)$ & $48(48)$ & \\
\hline
\end{tabular}

${ }^{\mathrm{a}}$ mean $\pm \mathrm{sd} ;{ }^{*}$ Effective $(\%) ;{ }^{\mathrm{E}}$ median [quartiles]

Table 4. Skin-to-skin correlation

\begin{tabular}{|l|l|l|l|}
\hline Variables & Odd ratio & IC & $\boldsymbol{p}$ \\
\hline Weight gain & 0.09 & {$[02-0.7]$} & 0.042 \\
\hline Respiratory distress & 0.25 & {$[0.5-0.96]$} & 0.035 \\
\hline Hypothermia & 1.8 & {$[2.1-4.3]$} & 0.028 \\
\hline
\end{tabular}

Neonatal medicine has progressed considerably in recent decades, allowing the survival of increasingly immature children, despite this, the ratio of neurological sequelae has changed little. [10]. So extraordinary cerebral growth occurs during the stay of the premature child in the hospital in our series $[11,12]$.

Obtaining good thermoregulation is a witness to the success of this practice. In our very low weight unit the skin to the skin is continuous. In our study, these mothers continued to breastfeed until 4 to 6 months after discharge.. Breastfeeding and skin practices contribute to a good relationship between the mother and the newborn and improve the neuro-developmental future of the newborn [4].

A recent meta-analysis of the effect of skin-to-skin in newborns concludes that the child has improved cardiorespiratory stability, decreased crying time, and increased breastfeeding [13].

Strategies based on breastfeeding support, skin-to-skin, parenting support allow the baby's environment to be adapted to its neurobehavioral development. Some care techniques have a welldocumented short-term effect. The average weight gain was $28 \pm 4 \mathrm{~g}$ with parental accompaniment while it was $15 \mathrm{~g}$ in those without skin to skin practices.

Skin-to-skin is a technique developing in neonatology units. This method has the advantage of associating postural support, a wrapping, the possibility of non-nutritive suction (mother's finger or breast), natural sensory stimulations (auditory, olfactory and taste) that can be adapted to Children [6], It has a demonstrated effect on physiological and motor stability, sleep protection, breastfeeding and attachment, which are important factors in the development of premature infants.

In our neonatology unit, we noted a mortality reduction of 60.4$19.3 \%$ in 2017 in premature infants since the introduction of skin-toskin practice.

\section{Conclusion}

Developmental care represents a new standard of care in neonatology of scientifically proven efficacy. Several elements supporting the importance of developmental care practices provided to the premature child have been clearly identified. They are essentially based on information and education of parents, training and support of health care team; if this practice has shown its effectiveness in developed countries, it is crucial to integrate it into neonatal care in our country. It will help to alleviate the lack of beds of neonatology for low birth weight.

\section{References}

1. Browne JV (2011) Developmental care for high-risk newborns: emerging science, clinical application, and continuity from newborn intensive care unit to community. Clin Perinatol 38: 719-729.

2. Glorieux I, Montjaux N, Casper C (2009) NIDCAP (Neonatal Individualized Developmental Care and Assessment Program) definition, practical aspects, published data. Arch Pediatr 16: 827-829. [Crossref]

3. Sandre D (2016) Developmental care and prevention of developmental difficulties in babies born prematurely. https://www.cairn.info/revue-spirale-2016-2-p-109.

4. Conde Agudelo A, Diaz-Rossello JL (2014) Kangaroo mother care to reduce morbidity and mortality in low birth weight infants. Cochrane Database Syst Rev 4: CD 002771.

5. Aube N, Delaitre C, Jarreau PH (2005) Skin : hygiene care and techniques of dermal monitoring in néonata resuscitation. J Obstet Gynecol Reprod Biol 34 : 79-83.

6. Pignol J, Lochelongue V, Flechelles O (2008) Skin to skin: a crucial contact for the newborn. Spiral.

7. Saigal S, Doyle LW (2008) An overview of mortality and sequelae of preterm birth from infancy to adulthood. Lancet 371: 261-269. [Crossref]

8. Charpak Ruiz PJG, Figueroa DCZ, Charpak Y (1997) Kangaroo mother versu traditional care for newborn infants 2000 grams: a randomised controlledtrial. Pediatrics 100: 682-628. [Crossref]

9. Ludington-Hoe SM, Nguyen N, Swinth JY, Satyshur RD (2000) Kangaroo care compared to incubators in maintaining body warmth in preterm infants. Biol Res Nurs 2: 60-73. [Crossref]

10. Lejeune Précarité et prématurité. J Pediatr Pueric 21: 344-348.

11. Faye PM (2016) Low birth weight newborn kangaroo care at the Albert-Royer National Children's Hospital in Dakar. ARCPED-4127.

12. Als H, Lawhon g, Brown E, Gibes R, Duffy FH, et al. (1986) Individualized behavioral and environmental Care for the very low birth weight preterm infant at high risk for bronchopulmonary Dysplasia: neonatal intensive care unit and developmental outcome. Pediatrics 78: 1123-1132.

13. Als H, Lawhon G, Duffy LH, McAnulty GB, Gibes-Grossman R, et al. (1994) Individualized developmental care for the very low- birth- weight preterm infant. Medical and neurofunctional effects. JAMA 272: 853-858. [Crossref]

Copyright: (C2018 Bouazza G. This is an open-access article distributed under the terms of the Creative Commons Attribution License, which permits unrestricted use, distribution, and reproduction in any medium, provided the original author and source are credited. 